\title{
Quasiclassical Trajectory Calculations of Acetaldehyde Dissociation on a Global Potential Energy Surface Indicate Significant Non-Transition State Dynamics
}

\author{
Benjamin C. Shepler, ${ }^{a}$ Bastiaan J. Braams ${ }^{\mathrm{b}}$ and Joel M. Bowman*,a \\ ${ }^{a}$ Department of Chemistry and Cherry L. Emerson Center for Scientific Computation, \\ Emory University, Atlanta, GA 30322; ${ }^{b}$ Department of Mathematics and Computer \\ Science, Emory University, Atlanta, GA 30322
}

Supplementary Information 

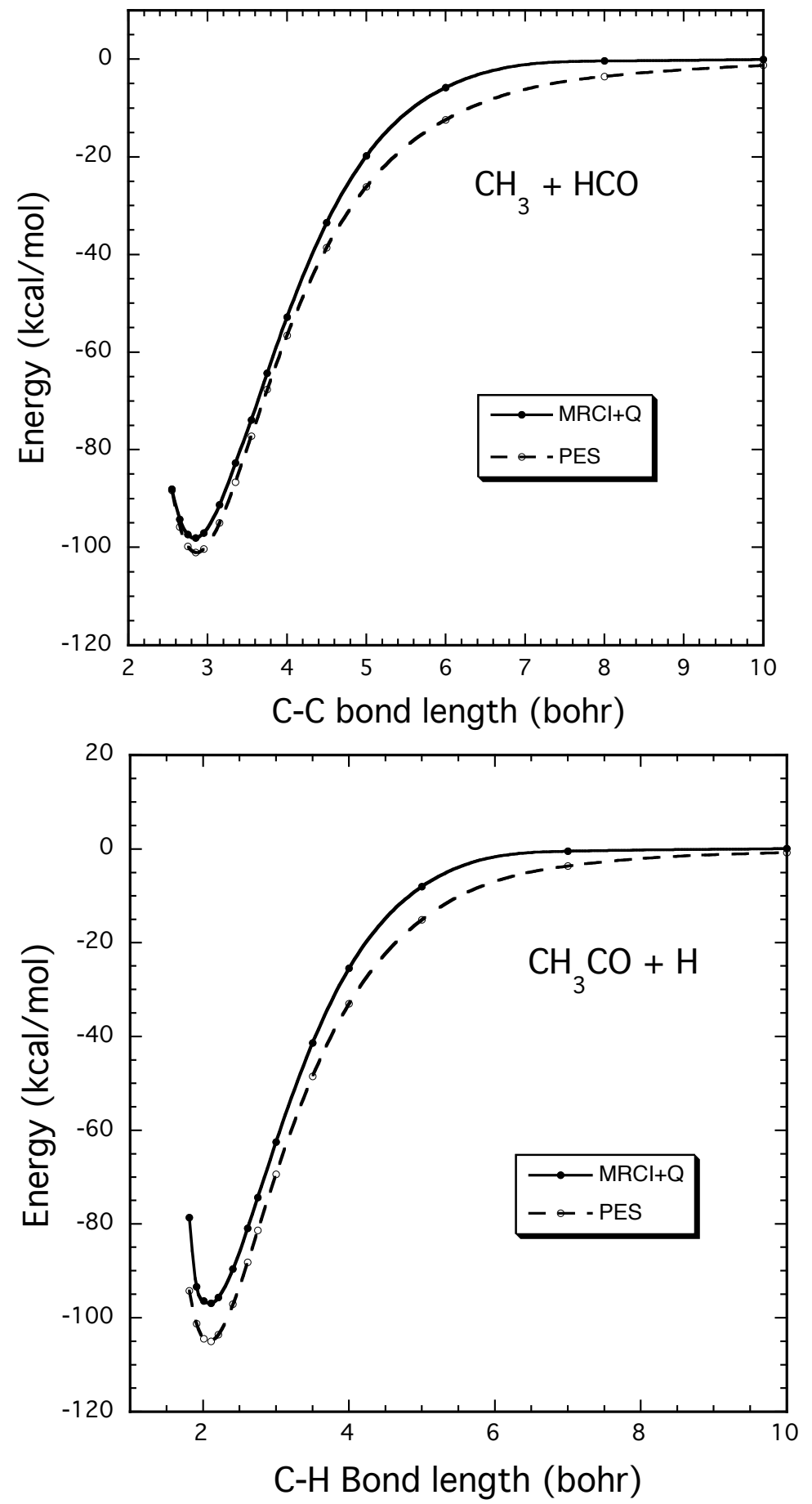

Figure S1 Comparison of 1d cut from PES and MRCI+Q calculations from a minimum to the separated fragments indicated. 

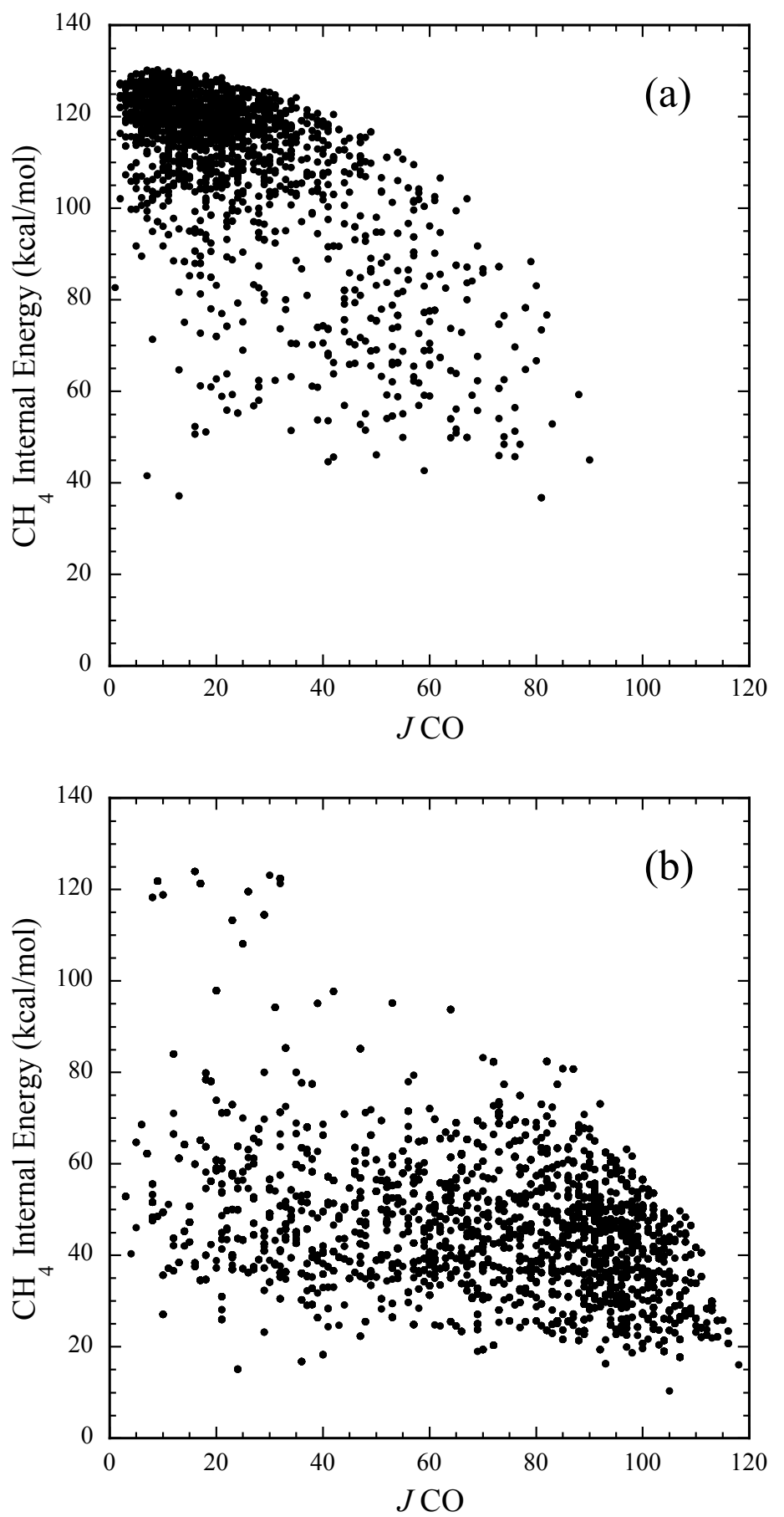

Figure S2: $\mathrm{CH}_{4}$ internal energy distributions versus $\mathrm{CO}$ rotational quantum number. (a) Trajectories initiated at acetaldehyde equilibrium geometry. (b) Trajectories initiated at the conventional transition state. 
(a) Acetaldyhyde

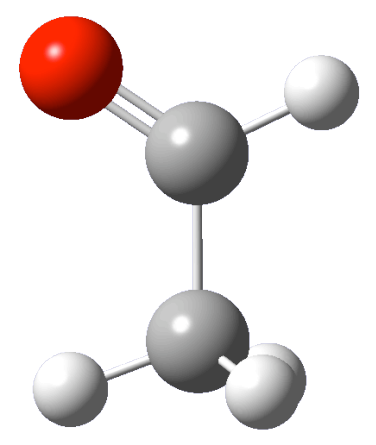

(c) Hydroxyethylidene

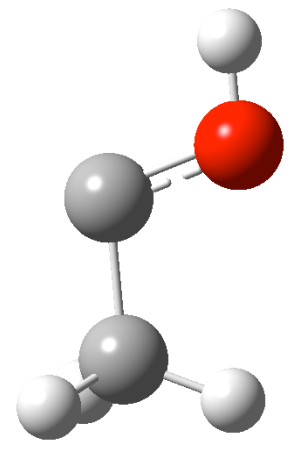

(e) TS (Acetaldehyde - Hydroxyethylidene)

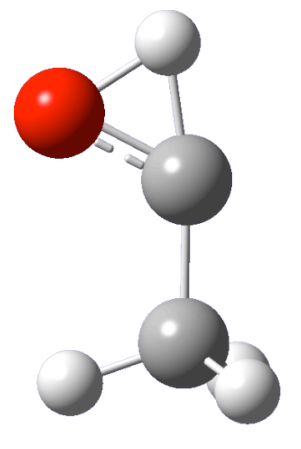

(b) Vinyl Alcohol

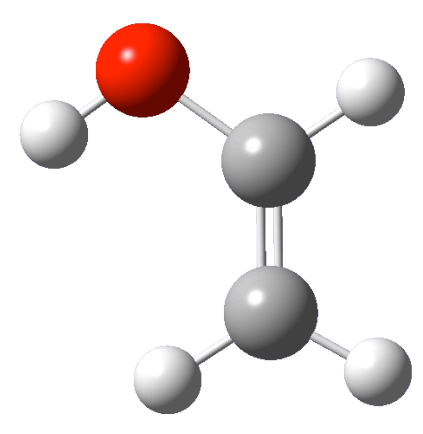

(d) TS (Acetaldehyde - Vinyl Alcohol)

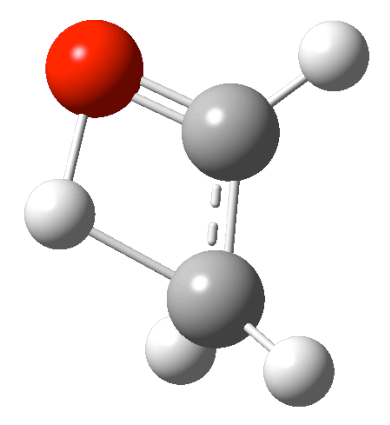

(f) TS (Acetaldehyde - $\mathrm{CH} 4+\mathrm{CO}$ )

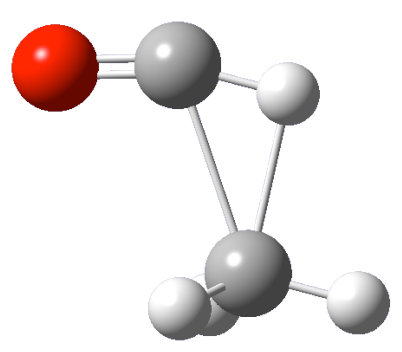

Figure S3: CCSD(T)/aug-cc-pVTZ optimized structures for selected stationary points on the $\mathrm{C}_{2} \mathrm{H}_{4} \mathrm{O}$ PES. 